\title{
Verification and Validation of Fire Dynamic Simulator for Enclosed Car Park
}

\author{
Ahmad Faiz Tharima, Md Mujibur Rahman, and Mohd Zamri Yusoff
}

\begin{abstract}
When fire occurs, smoke is detrimental to human health and interrupts the evacuation process if it is not controlled properly. Due to the existence of beams in a building, smoke tends to stagnate near the obstacles and recirculates, further delaying the evacuation process. In the current study, Fire Dynamic Simulator (FDS) is employed as a numerical tool to simulate smoke propagation. The numerical result is then compared with the available experimental data obtained from the literature. It is found that the agreement between the numerical and experimental results is promising. From this study, it is shown that FDS can indeed be used to model the smoke propagation in an enclosed car park; hence, it can be utilised to generate other CFD models related to fire simulation.
\end{abstract}

Index Terms-FDS, Verification,Validation, Car Park.

\section{INTRODUCTION}

Smoke management is part of the building code of a structural design. Improper smoke ventilation design causes smoke backflow that will eventually interrupt an evacuation process [1] and delay the fire extinguishment operation.Smoke tends to recirculate within the wake region behind an obstruction in the building. Smoke may be trapped in dead corners and pathways between the fire source and the exit[2-5]. According to [6]-[10], the smoke flow may be interrupted due to the presence of beam. However, research works related to the smoke backflow caused by the presence of beam are somehow limited.

The main objective of this paper is to build an accurate CFD model to predict the smoke propagation in the enclosed car park. In the current work, the geometry employed by Jie et al. [11] is used. As reported by [12-13], FDS is a reliable modelling tool that is able to reduce the number of experimentations.

\section{TEST DESCRIPTION}

The test-rig is $2 \mathrm{~m}$ in length and $0.5 \mathrm{~m}$ in height. Its width varies from $0.5 \mathrm{~m}$ and $1.5 \mathrm{~m}$. The plate of thickness $4 \mathrm{~mm}$ and the fire-resistant glass of thickness $30 \mathrm{~mm}$ are used to construct the ceiling, wall and floor. The other sidewall is movable, which is made of $8 \mathrm{~mm}$ thick fire-resistant glass for observation purpose. Methanol pool fire is used as the fire source. It is placed against the sidewall located at the longitudinal centre of the compartment. All pools are made of $2 \mathrm{~mm}$ thick steel plates of depth $20 \mathrm{~mm}$. Also, apparatus

Manuscript received November 10, 2016; revised March 1, 2017.

Ahmad Faiz Tharima is with the Center for Fluid Dynamics, College of Engineering, Universiti Tenaga Nasional (UNITEN), Putrajaya Campus, Jalan IKRAM-UNITEN, 43000 Kajang, Selangor, Malaysia (e-mail: pait.afz@gmail.com, ahmad.faiz@bomba.gov.my). such as mercury thermometer, thermocouples, radiation gauge and cameras are used to measure the ambient temperature, ceiling temperature and radiation level during the experiment. The experimental setup is shown in Figure 1. The ceiling temperatures are measured by K-type fine wire thermocouples of diameters $1 \mathrm{~mm}$. The response time of this thermocouple is less than 1s. The uncertainty of the measured data is estimated to be less than 5\%. The arrangements of the thermocouples placed below the ceiling are shown in Fig. 1. Two thermocouple trees with eight probes are positioned from $2 \mathrm{~cm}$ to $9 \mathrm{~cm}$ (with an interval of $1 \mathrm{~cm}$ ) below the ceiling. Thermocouple tree $A$ is placed $0.6 \mathrm{~m}$ longitudinally away from the pool centre and thermocouple tree $\mathrm{B}$ is positioned $0.4 \mathrm{~m}$ transversely away from the sidewall.

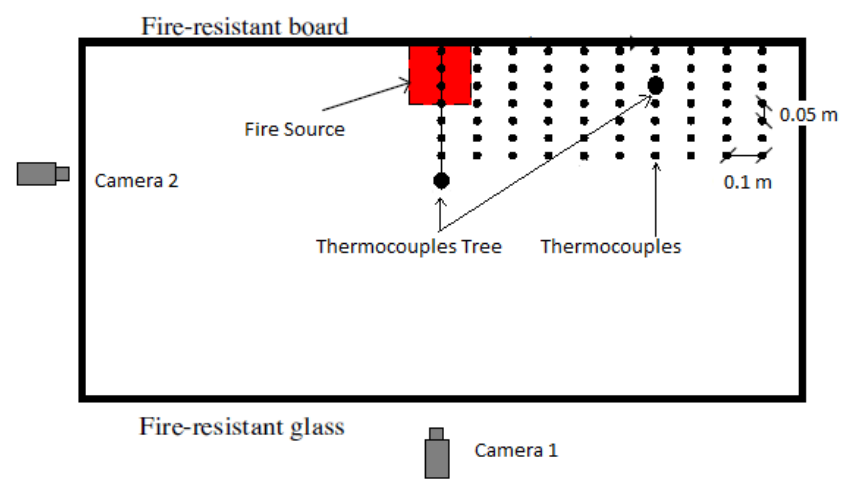

Fig. 1. Diagram of experimental test rig.

\section{METHODS}

In order to validate the FDS model [14], the numerical results obtained by employing different mesh sizes are compared with the established experimental data reported by Ji et al [11]. Here, the Large Eddy Simulation is employed to model the flow turbulence.

FDS solves the governing equations of the fire-driven fluid flow in any enclosure. A lot of fire simulations have been performed by other researchers such as [4,12,13,15-24] due to the reliability of FDS.

The numerical settings of the simulation are described in Table II. The heat release rate is shown in Figure 2 for the case of $\mathrm{H}_{\mathrm{ef}}=0.15$, where $\mathrm{H}_{\mathrm{ef}}$ is the distance between the ceiling and the floor. This curve is generated from the data reported by Jie et al. [11]. The simulation is executed for 635 seconds and the detailed results are shown in Table 1. In FDS, the nominal Heat Release Rate per Unit Area (HRRPUA) is multiplied by RAMP in order to generate the curve shown in Figure 2. The total heat release rate is then 
obtained by multiplying the HRRPUA by the total surface area of the fire.

There are a few assumptions made in the current study:

1) The ceiling, floor and side walls are adiabatic.

2) The uncertainties of the thermocouples are estimated to be less than $5 \%$.

3) Possible wind effects are not taken into account.

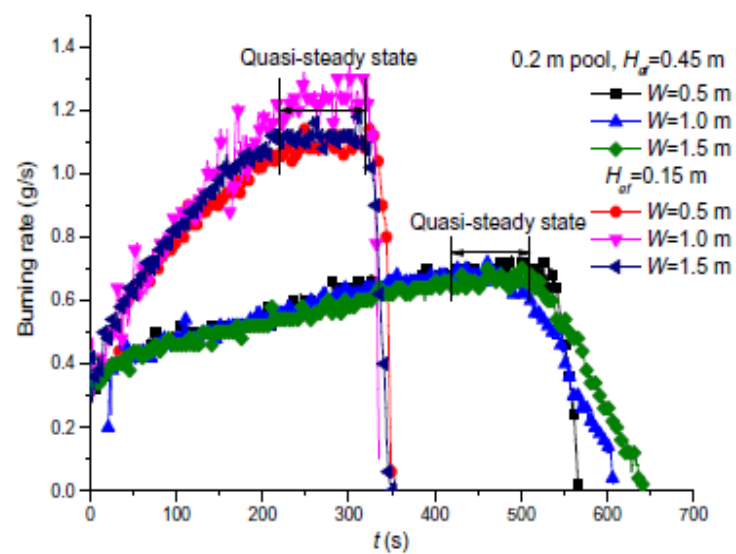

Fig. 2. Burning rate versus time.

TABLE I: 635 SECONDS OF THE HRR CURVE

\begin{tabular}{cccccc}
\hline \hline \multicolumn{5}{c}{ HRR max $(\mathrm{kW})=$} & \multicolumn{3}{c}{9.38} & \\
\hline Time & HRR & Fraction & Time & HRR & Fraction \\
\hline 0 & 0.0 & 0 & 311.36 & 8.0 & 0.85 \\
3.33 & 3.5 & 0.37 & 323.9 & 7.97 & 0.85 \\
11.08 & 3.9 & 0.42 & 334.55 & 8.54 & 0.91 \\
17.87 & 4.3 & 0.46 & 344.18 & 8.44 & 0.9 \\
25.62 & 4.8 & 0.51 & 358.68 & 8.72 & 0.93 \\
36.24 & 4.8 & 0.51 & 368.3 & 8.44 & 0.9 \\
45.92 & 5.2 & 0.55 & 377.96 & 8.72 & 0.93 \\
55.58 & 5.4 & 0.58 & 393.39 & 8.72 & 0.93 \\
61.35 & 5.2 & 0.55 & 407.88 & 8.82 & 0.94 \\
75.85 & 5.6 & 0.6 & 421.36 & 8.72 & 0.93 \\
84.53 & 5.6 & 0.6 & 434.86 & 8.72 & 0.93 \\
92.27 & 6.0 & 0.64 & 449.34 & 8.82 & 0.94 \\
102.86 & 5.7 & 0.61 & 463.85 & 9.29 & 0.99 \\
114.44 & 5.9 & 0.63 & 483.11 & 9.00 & 0.96 \\
125.05 & 5.9 & 0.63 & 502.43 & 9.38 & 1 \\
132.81 & 6.5 & 0.69 & 515.88 & 8.72 & 0.93 \\
148.24 & 6.5 & 0.69 & 525.48 & 8.25 & 0.88 \\
165.61 & 6.5 & 0.69 & 535.1 & 7.97 & 0.85 \\
175.27 & 6.8 & 0.72 & 542.74 & 7.13 & 0.76 \\
189.74 & 6.8 & 0.72 & 556.18 & 6.47 & 0.69 \\
203.24 & 6.8 & 0.72 & 565.8 & 6.00 & 0.64 \\
215.81 & 7.0 & 0.75 & 571.73 & 5.44 & 0.58 \\
227.38 & 7.0 & 0.75 & 576.27 & 4.50 & 0.48 \\
238.95 & 7.1 & 0.76 & 582.97 & 3.94 & 0.42 \\
248.62 & 7.3 & 0.78 & 591.59 & 3.19 & 0.34 \\
259.23 & 7.3 & 0.78 & 598.29 & 2.63 & 0.28 \\
267.93 & 7.6 & 0.81 & 604.98 & 1.97 & 0.21 \\
276.63 & 7.9 & 0.84 & 610.74 & 1.69 & 0.18 \\
283.36 & 7.6 & 0.81 & 614.54 & 0.94 & 0.1 \\
294.96 & 8.0 & 0.85 & 627.03 & 0.38 & 0.04 \\
302.66 & 7.7 & 0.82 & 635.6 & -0.84 & -0.09 \\
\hline \hline
\end{tabular}

The governing equations in CFDare:

1) Conservation of mass

$$
\frac{\partial \rho}{\partial t}+\nabla \cdot \rho \mathrm{u}=\dot{\mathrm{m}}_{\mathrm{b}}^{\prime \prime \prime}
$$

2) Conservation of momentum

$$
\frac{\partial}{\partial t}(\rho u)+\nabla \cdot \rho u u+\nabla p=\rho g+f_{b}+\nabla \cdot \tau_{i j}
$$

3) Conservation of energy

$$
\frac{\partial}{\partial t}(\rho \mathrm{h})+\nabla \cdot \rho \mathrm{hu}=\frac{\mathrm{Dp}}{\mathrm{Dt}}+\mathrm{q}^{\prime \prime \prime}-\dot{\mathrm{q}}_{\mathrm{b}}^{\prime \prime \prime}-\nabla \cdot \mathrm{q}^{\prime \prime \prime}
$$

TABLE II: BOUNDARY CONDITIONS FOR THE SIMULATION

\begin{tabular}{ll}
\hline \hline Parameter & Description \\
\hline Geometry dimension & $1.5 \mathrm{~m} \times 2 \mathrm{~m} \times 0.5 \mathrm{~m}$ \\
Mesh size & $3.57 \mathrm{~cm}, 1.47 \mathrm{~cm}, 0.94 \mathrm{~cm}$ \\
HRRPUA & $234.5 \mathrm{~kW} / \mathrm{m}^{2}$ \\
Fuel & Methane $\left(\mathrm{CH}_{4}\right)$ \\
CO yield & 0.2 \\
Soot yield & 0.07 \\
Hydrogen Fraction & 0.1 \\
Fire source area & $0.2 \mathrm{~m} \times 0.2 \mathrm{~m}$ \\
Combustion model & default mixture fraction \\
& combustion model \\
Turbulence model & standard Smagorinsky LES, \\
& $\mathrm{C}_{\mathrm{D}}=0.20$ \\
\hline \hline
\end{tabular}

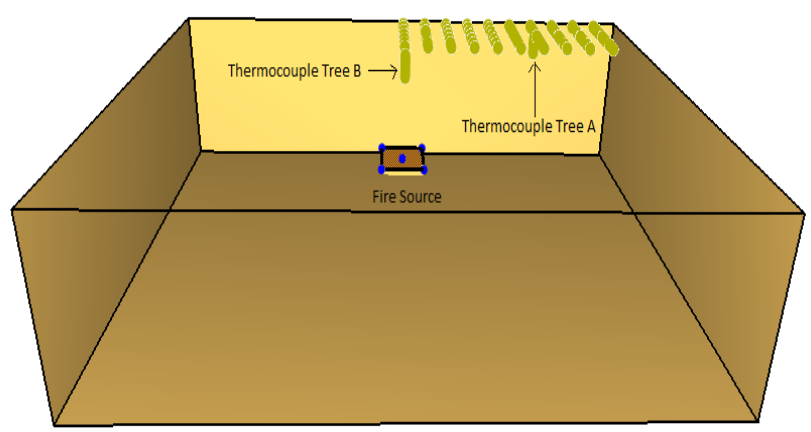

Fig. 3. Boundary conditions.

\section{RESUlTS AND DisCUSSION}

Grid sensitivity study is performed in the current work. Figures 4-5 show the ceiling temperature computed by using grid sizes of $3.57 \mathrm{~cm}, 1.47 \mathrm{~cm}$ and $0.94 \mathrm{~cm}$ for the first 500 seconds. The completion time of the case employing the coarsest mesh is only a few hours (single 2.5-GHz Intel i7 processor) whereas the finest grid case requires 18 days or 425 hours as shown in Table III. As the grid is refined, the result comes closer to the maximum heat release rate. As the main purpose of the current study is to measure the smoke backlayering distance and the smoke layer level, the mesh count employed in the current work is already sufficient to capture the required flow phenomena.

TABLE III: GENERAL FEATURES USED

\begin{tabular}{ccccc}
\hline \hline Mesh & $\begin{array}{c}\text { Mesh } \\
\text { size } \\
(\mathbf{c m})\end{array}$ & $\begin{array}{c}\text { Number } \\
\text { of cells }\end{array}$ & $\begin{array}{c}\text { Time Step } \\
\text { (Convergence) }\end{array}$ & $\begin{array}{c}\text { Total } \\
\text { Time } \\
\text { (hour) }\end{array}$ \\
\hline Coarse & 3.57 & 32,928 & 51766 & 4.4 \\
Moderate & 1.47 & 471,648 & 166,467 & 107.85 \\
Fine & 0.94 & $1,797,760$ & 275,700 & 403.7 \\
\hline \hline
\end{tabular}




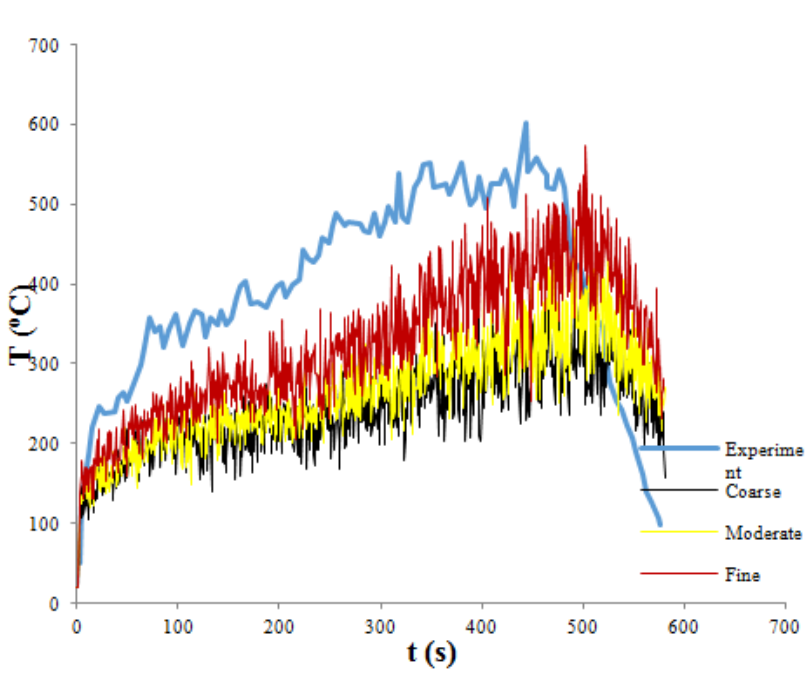

Fig. 4. Temperatures below the ceiling with $0.01 \mathrm{~m}$ away the sidewall.

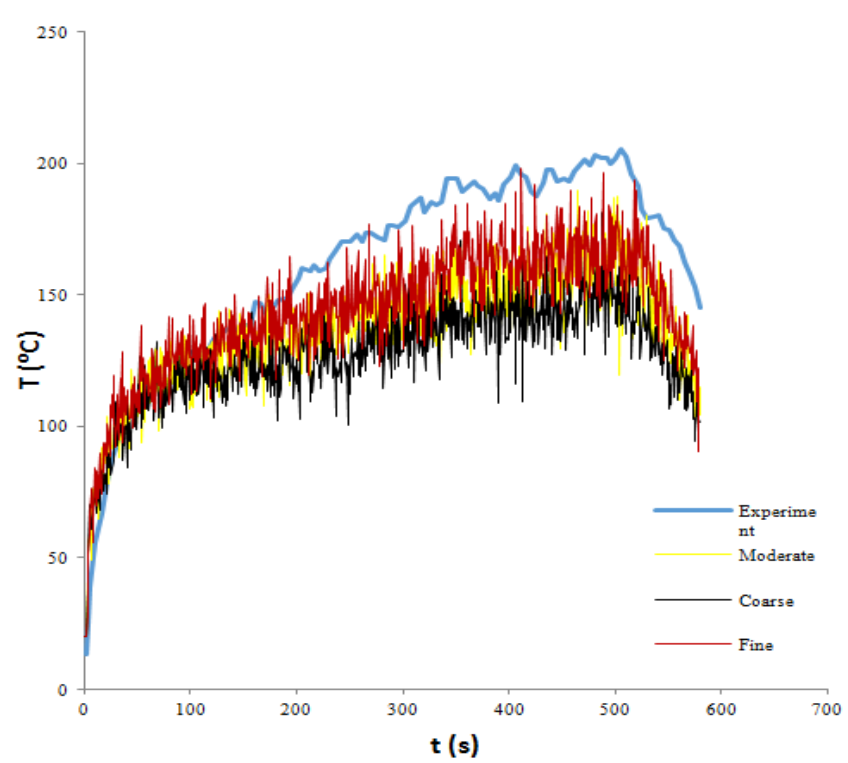

Fig. 5. Temperatures at thermocouple tree A with 0.01 below the ceiling

The percentage difference between the FDS prediction and the experimental value is presented in Table IV. Here, the following grading convention is used:

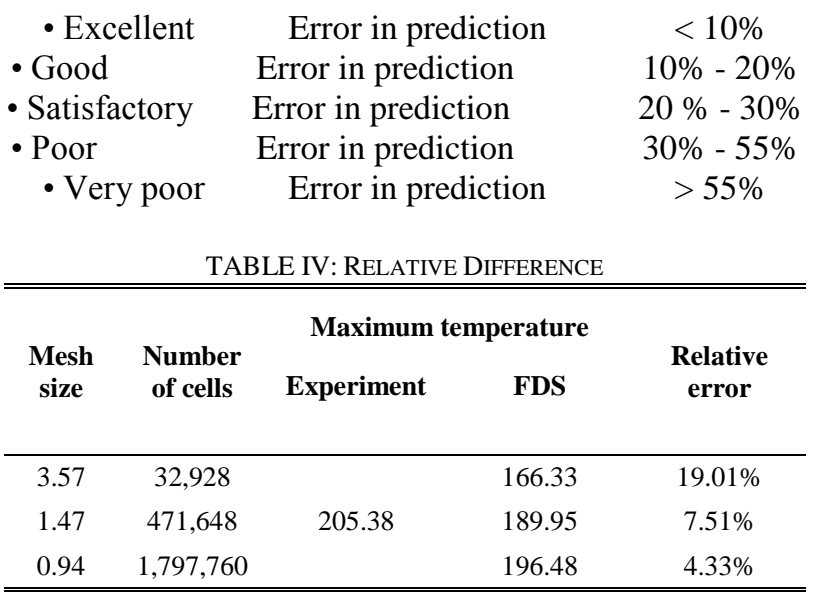

As observed, the error is $19 \%$ as the coarse grid is employed. This error, however, can be decreased as the grid is refined. At the finest mesh level, the error is only $4.33 \%$.

\section{CONCLUSION}

This study has verified and validated the CFD model which is used to examine the effect of beam configuration in the enclosed car park on the smoke propagation. The CFD results, which are generated by using FDS, agree considerably well with the previous experimental data. It has been found that the numerical result is coming closer to the measured data as the grid is refined. Based on the current findings, it is believed that FDS serves as a reliable tool to solve CFD problems related to fire dynamics.

\section{ACKNOWLEDGMENT}

The current study was supported by a scholarship provided by MalaysiaPublic Service Department to the first author.

\section{REFERENCES}

[1] P. A. Enright, "Impact of jet fan ventilation systems on sprinkler activation," Case Stud. Fire Saf, vol. 1, 2014, pp. 1-7.

[2] R. Vettori, Effect of a Beamed, Sloped, and Sloped Beamed Ceilings on the Activation Time of a Residential Sprinkler, 2003.

[3] Marian et al., Smoke Control and Noxes in Car Parks, vol. 18, 2012, pp. 94-101.

[4] B. Merci and M. Shipp, "Smoke and heat control for fires in large car parks: Lessons learnt from research?," Fire Saf. J., vol. 57, 2013, pp. 3-10.

[5] M. Deckers, "Haga, tilley, smoke control in case of fire in a large car park: Full-scale experiments," Fire Saf. J., vol. 57, 2013, pp. 22-34.

[6] C. Koslowski and V. Motevalli, Behavior of a 2-Dimensional Ceiling Jet Flow: A Beamed Ceiling Configuration, 1994, pp. 469-480.

[7] C. C. Koslowski and V. Motevalli, "Effect of beams on ceiling jet behavior and heat detector operation," J. Fire Prot. Eng., vol. 5, 1993, pp. 97-111.

[8] V. Motevalli and Z. P. Yuan, "Steady state ceiling jet behavior under an unconfined ceiling with beams," Fire Technol, vol. 44, 2008, pp. 97-112.

[9] C. C. Siang, "Characterizing smoke dispersion along beamed ceilings using salt-water modeling," 2010.

[10] Delichatsios, The Flow of Fire Gases Under a Beamed Ceiling, 1981.

[11] J. Ji, Y. Y. Fu, C. G. Fan, Z. H. Gao, and K.Y. Li, "An experimental investigation on thermal characteristics of sidewall fires in corridor-like structures with varying width," Int. J. Heat Mass Transf, vol. 84, 2015, pp. 562-570.

[12] N. Tilley, P. Rauwoens, and B. Merci, "Verification of the accuracy of CFD simulations in small-scale tunnel and atrium fire configurations," Fire Saf. J., vol. 46, 2011, pp. 186-193.

[13] B. Zhang, J. Zhang, S. Lu, and C. Li, "Buoyancy-driven flow through a ceiling aperture in a corridor: A study on smoke propagation and prevention, Build," Simul, vol. 8, 2015, pp. 701-709.

[14] K. McGrattan, S. Hostikka, R. McDermott, J. Floyd, C. Weinschenk, and K. Overholt, Sixth Edition Fire Dynamics Simulator Technical Reference Guide.

[15] X. Deckers, S. Haga, B. Sette, and B. Merci, "Smoke control in case of fire in a large car park : Full-scale experiments," Fire Saf. J., vol. 57, 2013, pp. 11-21.

[16] N. Meng, L. Hu, S. Zhu, and L. Yang, "Effect of smoke screen height on smoke flow temperature profile beneath platform ceiling of subway station: An experimental investigation and scaling correlation," Tunn. Undergr. Sp. Technol., vol. 43, 2014, pp. 204-212.

[17] I. Horváth, J. V. Beeck, and B. Merci, "Full-scale and reduced-scale tests on smoke movement in case of car park fire," Fire Saf. J., vol. 57, 2013, pp. 35-43.

[18] S. Lu, Y. H. Wang, R. F. Zhang, and H. P. Zhang, "Numerical study on impulse ventilation for smoke control in an underground car park," Procedia Eng., vol. 11, 2011, pp. 369-378.

[19] R. N. Meroney, D. W. Hill, R. Derickson, J. Stroup, K. Weber, and P Garrett, "CFD Simulation of ventilation and smoke movement in a large military firing range," Jnl. Wind Eng. Ind. Aerodyn, vol. 136, 2015, pp. 12-22.

[20] NFPA 92, Standard for Smoke Control Systems, 2012.

[21] W. Poh, "Tenability criteria for design of smoke hazard management systems," Forum Am. Bar Assoc, 2011. 
[22] P. Rudolf, M. Hudec, P. Zubík, and D. Štefan, "Comparison of CFD simulations and measurements of flow affected by Coanda effect," EPJ Web Conf., vol. 25, 2012.

[23] M. Santoso, M.A. Bey, Y. S. Sulistyo, and Z. Nugroho, "CFD study on the ventilation system and shape configuration of underground car park in case of fire," Appl. Mech. Mater., vol. 758, 2015, pp. 143-151.

[24] N. Tilley, X. Deckers, and B. Merci, "CFD study of relation between ventilation velocity and smoke backlayering distance in large closed car parks," Fire Saf. J., vol. 48, 2012, pp. 11-20.

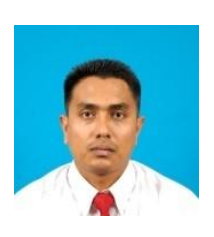

Ahmad FaizTharimahas received his master in technology management from Universiti Malaysia Pahang and received his bachelor engineering degree in civil engineering from Universiti Teknologi Malaysia. Currently, he is pursuing his $\mathrm{PhD}$ in mechanical engineering at the Centre for Fluid Dynamics, College of Engineering, Universiti Tenaga Nasional. He is working at Malaysia Fire and Rescue Departmernt. His research interests include FDS, smoke management, and optimisation. 